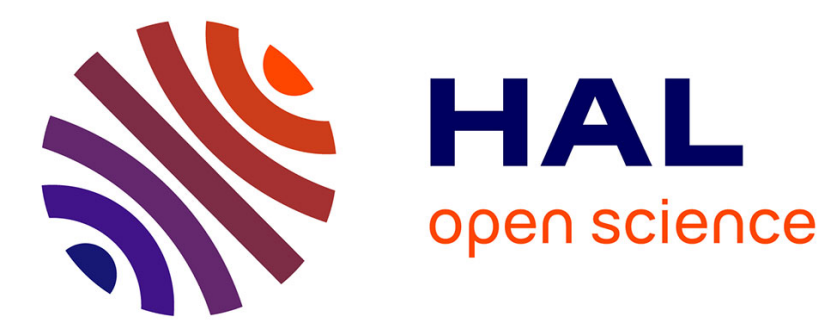

\title{
Modelling the radiowave propagation with a split-step wavelet method for radio occultation
}

Rémi Douvenot, Alexandre Chabory, Sébastien Rougerie

\section{To cite this version:}

Rémi Douvenot, Alexandre Chabory, Sébastien Rougerie. Modelling the radiowave propagation with a split-step wavelet method for radio occultation. MIKON 2018 22nd International Microwave and Radar Conference, May 2018, Poznan, Poland. pp. 562-564, 10.23919/MIKON.2018.8405285 . hal01839331

\section{HAL Id: hal-01839331 \\ https://hal-enac.archives-ouvertes.fr/hal-01839331}

Submitted on 16 Jul 2018

HAL is a multi-disciplinary open access archive for the deposit and dissemination of scientific research documents, whether they are published or not. The documents may come from teaching and research institutions in France or abroad, or from public or private research centers.
L'archive ouverte pluridisciplinaire HAL, est destinée au dépôt et à la diffusion de documents scientifiques de niveau recherche, publiés ou non, émanant des établissements d'enseignement et de recherche français ou étrangers, des laboratoires publics ou privés. 


\section{Modelling the Radiowave Propagation with a Split-Step Wavelet Method for Radio Occultation}

\author{
Rémi Douvenot \\ ENAC, TELECOM \\ Univ de Toulouse \\ 31055 Toulouse, France \\ Email: douvenot@ recherche.enac.fr
}

\author{
Alexandre Chabory \\ ENAC, TELECOM \\ Univ de Toulouse \\ 31055 Toulouse, France \\ Email: chabory@recherche.enac.fr
}

\author{
Sébastien Rougerie \\ Centre National d'Études Spatiales \\ 31401 Toulouse, France \\ Email: sebastien.rougerie@cnes.fr
}

\begin{abstract}
This paper introduces the split-step wavelet (SSW) propagation technique applied to radio occultation (RO). This technique accounts for both a complex atmosphere and the ground reflection. It is applied on a scenario between a GPS satellite and a low-elevation orbit satellite. The atmosphere is modelled using an ITU model. The Earth is considered as a sphere. We show that the atmosphere and ground effects are both visible at the receiving satellite. Therefore, $\mathrm{SSW}$ is a good candidate for RO propagation modelling.
\end{abstract}

Index Terms-split-step wavelet, radio occultation, GPS signal, propagation.

\section{INTRODUCTION}

Radio occultation (RO) consists in inferring the atmospheric conditions from satellite-to-satellite radiowave measurements when the satellites are at the limit of the line-of-sight configuration. In this condition, the radiowave propagation is significantly altered by the variations of the atmosphere in the lowest layers. This alteration carries information about the propagation channel.

On Earth, RO is often applied with GNSS signals of opportunity since lots of transmitters are available [1]. Therefore, we consider a geometry with a GPS transmitter and a dedicated low-elevation orbit (LEO) satellite as a receiver.

A simple one-ray model is often used to model the propagation and infer the atmospheric conditions. However, efforts are made by the community to develop more accurate models [2]. In this context, the aim of this paper is to demonstrate the usability of the recently developed split-step wavelet (SSW) algorithm [3] for RO. This method considers the atmosphere using phase screens. Compared to the one-ray model, SSW can deal with any atmosphere varying in both altitude and distance. Moreover, the ground relief and composition can be accounted. For this study, we consider the Earth as a sphere. The atmosphere is defined from an ITU model [4]. In the end, the impacts of the atmospheric layers on the magnitude, group and phase delays, and Doppler shift received on the LEO satellite are expected to be accurately quantified.

In the first section, SSW and the atmospheric model are briefly introduced. Simulation results are presented in the second section. Finally, the relevancy to use accurate models as SSW is discussed in the conclusion.

\section{The Electromagnetic MOdelling}

\section{A. Atmospheric model}

In this paper, we consider the atmospheric model P835-6 proposed by ITU [4]. This model allows for the calculation of the refractive index $n$ with respect to standard values of the pressure, humidity, and temperature on Earth. This model is used here as an example. More complex atmospheric models could be used without modifying the propagation method itself.

We only model the troposphere. Ionosphere may be included in the global atmospheric model by using (for example) the ITU-R P531. However, as the refractive index is very close to one in the ionosphere, there is almost no refraction. Thus we decide to neglect it to reduce our computation domain.

\section{B. Split-step wavelet propagation method}

The radiowave is propagated using the split-step wavelet (SSW) method. This method is inspired by the split-step Fourier (SSF) method. The main difference with SSF is that the field is decomposed on wavelets instead of plane waves. The wavelet decomposition has the advantage of being fast and rendering a sparse representation of the signal [5].

The propagation method is described in details in [3] and briefly summarised here. The field is supposed known on a first vertical. The propagation is performed iteratively following these steps: the field is represented as a sparse wavelet vector by applying the fast wavelet transform (FWT) and compression. Then, the propagation on a step $\Delta x$ is considered using a precomputed wavelet-to-wavelet scattering matrix. A sparse wavelet vector after free-space propagation on $\Delta x$ is obtained. Then, an inverse FWT gives the corresponding field.

Finally, the refractivity and relief are accounted in the space domain like for SSF. The ground is accounted by means of a dedicated local image method. This method is performed iteratively in distance to obtain the complete field.

SSW is validated in [3] by comparisons with analytically propagated complex source points in free space and with SSF on complex scenarios. The additional RMS error due to the matrix compression follows $E_{\mathrm{M}}=N_{x} V_{\mathrm{M}}$, where $V_{\mathrm{M}}$ is the compression threshold for the precomputed wavelet-to-wavelet scattering matrix. The additional RMS error due to the fields compression during the propagation follows $E_{\mathrm{s}}=N_{x}^{0.3} V_{\mathrm{s}}$, where $V_{\mathrm{s}}$ is the compression threshold applied on the field at 
each step. Finally, the maximal expected RMS error due to the wavelet compressions is given by $E_{\mathrm{tot}}=E_{\mathrm{M}}+E_{\mathrm{s}}$.

Therefore, the simulation methods fulfils the same limitations as SSF, with an acceptable and tunable error.

Here, the propagation domain is separated in 3 areas: the ground is accounted in the second one only.

\section{NUMERICAL SIMULATIONS}

\section{A. Configuration}

We consider a GPS satellite at frequency $f=1.575 \mathrm{GHz}$ with a gain of $16 \mathrm{dBi}$ and a power of $25 \mathrm{~W}$. The receiver is positioned on a LEO satellite. The RO configuration is chosen such that the trajectory between the GPS and the LEO satellites is tangent to Earth. The total distance between the satellites is $29200 \mathrm{~km}$.

Concerning the computation domain, the aim is to find the best trade-off between a domain large enough to model all the physical contributions of the RO process and an acceptable computation time. As we assume no ionosphere, we use a 2D plane of height $50 \mathrm{~km}$. Moreover, the first vertical is set at $x=24647 \mathrm{~km}$. The chosen steps are $\Delta z=4 \mathrm{~m} \approx 20 \lambda$ and $\Delta x=1000 \mathrm{~m}$. Finally, the size of the computation domain is $50 \times 4553 \mathrm{~km}^{2}$, i.e., $12500 \times 4553$ points.

The compression thresholds are chosen as $V_{\mathrm{M}}=2 \times 10^{-7}$ and $V_{\mathrm{s}}=10^{-4}$. Therefore, the additional modelling error due to the wavelet compression is $-53 \mathrm{~dB}$, which is negligible.

The polarisation is TE. Circular polarisations could be obtained with 2 simulations in TE and TM. Note that the coarse discretisation along $z$ implies that the calculation is only valid for propagation angles close to the main propagation direction. This is not an issue considering the geometry of RO.

The refractive index obtained with the ITU model is represented in figure 1. As expected, the variation of the refractive index is stronger close to the Earth surface. The position of the LEO satellite corresponds to the vertical distance $0 \mathrm{~km}$ at range $4553 \mathrm{~km}$.

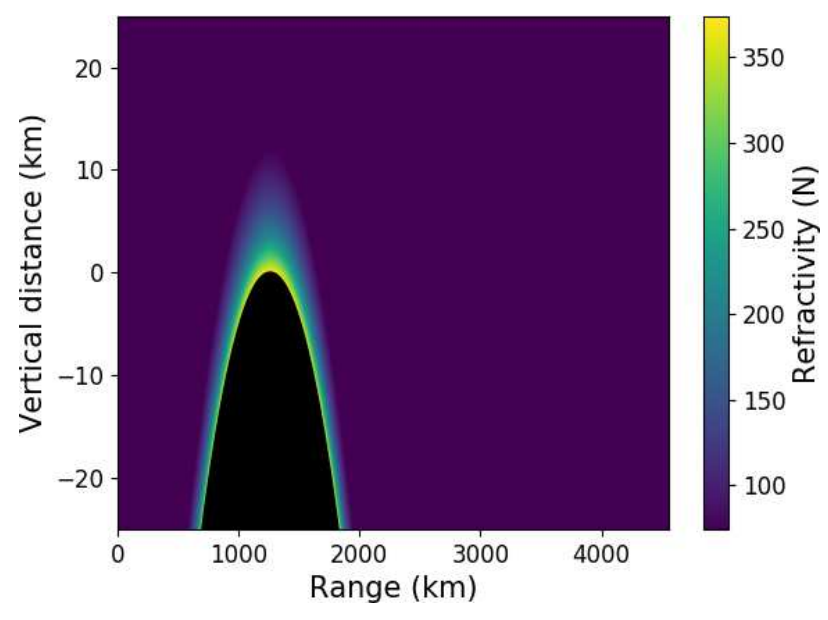

Fig. 1. $\mathrm{N}$ index along the propagation scene. Earth is in black.

\section{B. Results}

The electric field obtained with respect to the horizontal and vertical distances is plotted in figure 2 . The vertical white dotted lines show the separations between the 3 calculation zones. The ground in accounted in the second one only. Calculation time of SSW is approximately $10 \mathrm{~min} 30 \mathrm{~s}$ on a standard computer with a $2.7 \mathrm{GHz}$ processor. One can see that the Earth surface is accounted. The bending due to atmosphere is also visible. Few numerical artefacts due to the coarse vertical meshing can be observed, without influence on the field calculated at the LEO.

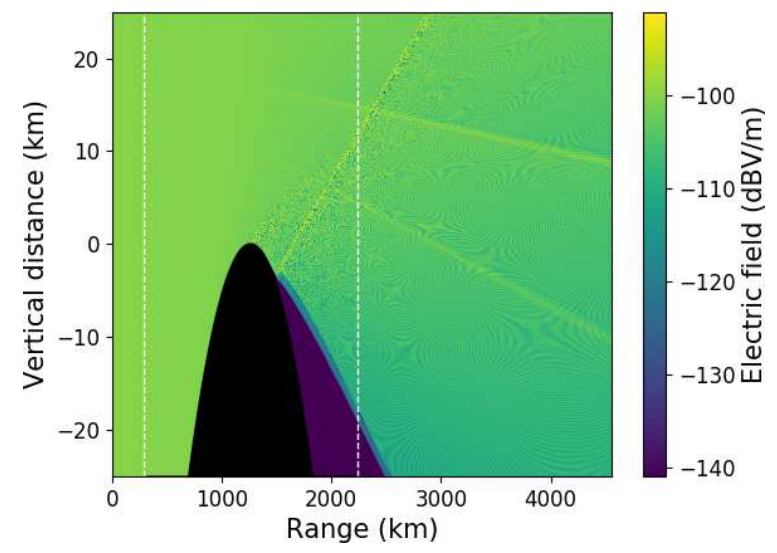

Fig. 2. Electric field with respect to horizontal and vertical distances.

The field on the last vertical $500 \mathrm{~m}$ on each side of the LEO satellite is plotted in figure 3 . The variability of the field with respect to the position is strong. Indeed, the reflection over Earth has here a significant effect.

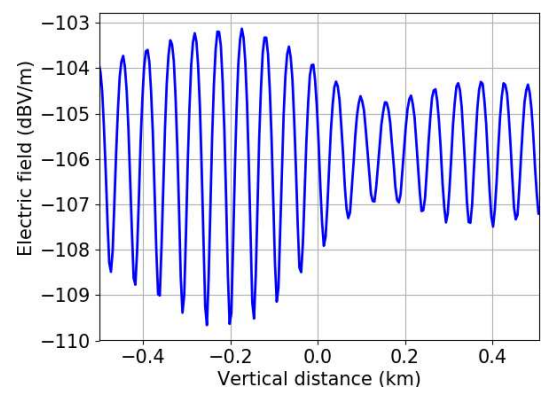

Fig. 3. Electric field with respect to the vertical distance on the last vertical.

\section{Discussion}

This paper introduces split-step wavelet (SSW) to calculate propagation for radio occultation (RO). We have shown that accurate electromagnetic modelling including atmosphere and ground can be used rather than a simplified one-ray method. This study has also shown the ability of SSW to deal with very large scenes (12500 vertical points).

The main interest of SSW is to simulate propagation in complex environments. Complex refractive index and relief can be used as input. Moreover, simulations can be performed in acceptable times - typically few minutes or tens of minutes for one scene on a standard computer.

The second interest of SSW is to consider the ground reflection. The relevance of considering the ground is still to be discussed. The reflected wave is mainly in cross-polarisation. 
Nevertheless, the antenna polarisations are not pure and a modelling considering both transmission and reception antennas should be lead to investigate this question.

\section{REFERENCES}

[1] E. R. Kursinski, G. A. Haji, J. T. Schofield, R. P. Linfield, and K. R. Hardy, "Observing Earth's atmosphere with radio occultation measurements using the Global Positioning System," Journal of Geophysical Research, vol. 102, pp. 23 429-23 465, 1997.

[2] C.-A. L'Hour, V. Fabbro, A. Chabory, and J. Sokoloff, "2D modeling of the atmospheric refraction based on Gaussian beams," in 10th European Conference on Antennas and Propagation (EuCAP), April 2016, pp. 1-3.

[3] H. Zhou, A. Chabory, and R. Douvenot, "A fast split-step wavelet algorithm for the simulation of long-range propagation," IEEE Transactions on Antennas and Propagation, submitted.

[4] ITU, "Reference standard atmospheres," ITU-R P.527-3, Tech. Rep., 2017

[5] S. Mallat, A Wavelet Tour of Signal Processing. Academic press, 1999. 